\title{
Anti-Tuberculosis Commodities Management Performance and Factors Affecting It at Public Health Facilities in Dire Dawa City Administration, Ethiopia
}

This article was published in the following Dove Press journal:

Journal of Multidisciplinary Healthcare

\author{
Fasika Berhanu Tola' \\ Gizachew Tilahun Anbessa ${ }^{2}$ \\ Berhan Begashaw Yikna $\mathbb{D}^{3}$ \\ 'Curative and Rehabilitative Core \\ Process Section, Dire Dawa City \\ Administrative Health Bureau, Dire \\ Dawa, Ethiopia; ${ }^{2}$ School of Pharmacy, \\ Faculty of Health Science, Jimma \\ University, Jimma, Ethiopia; ${ }^{3}$ Department \\ of Pharmacy, College of Health Science, \\ Debre Berhan University, Debre Berhan, \\ Ethiopia
}

Background: Health facilities (HFs) need extensive ranges of anti-tuberculosis (TB) drugs and related TB laboratory commodities (LCs) for diagnosis, prevention, and treatment of TB and multi-drug-resistance (MDR)-TB. This study was aimed to assess anti-TB commodities management performance at public HFs of Dire Dawa city administration, Ethiopia.

Methods: A cross-sectional study design in $16 \mathrm{HFs}$ providing TB and MDR-TB related service using quantitative and qualitative method was conducted. Semi-structured questionnaires and observation checklists with logistic indicators assessment tools were used to collect data. We used an in-depth interview and analyzed using a thematic approach. Quantitative data were entered into Epi-Data version 3.1 and transported to SPSS version 20 to analyze the results. Chisquare was used to test the association and a $P$-value $<0.05$ was statistically significant.

Results: The majority $(13 ; 81.3 \%)$ of HFs used a health commodity management information system. Forty-two (40\%) bin cards (BCs) for first line anti-TB drugs were not updated, while $62.5 \%$ of BCs were updated for second line drugs. On average, $43 \%$ of HFs accurately reported a report and requisition format (RRF) had significant association with the presence of a logistic management information system (LMIS) and standard operating procedure $(P=0.019)$. Of the HFs, $50 \%$ had good storage conditions and guidelines $(P=0.041)$. Regimen change $(56.3 \% ; P=0.035)$, receive near expiry $(56.3 \% ; P=0.035)$, and defective practice to first expired-first-out $(50 \% ; P=0.007)$ were reasons for wastages. About $50 \%$ and $66.6 \%$ of HFs were stocked out for isoniazid $300 \mathrm{mg}$, rifampicin, isoniazid, pyrazinamide (RHZ fixed dose), and ethambutol $400 \mathrm{mg}$ with a mean stock out duration of 10.8, 18.9, and 70.5 days, respectively. Regimen change $(68.8 \% ; P=0.026)$, low demand $(56.3 \% ; P=0.041)$, and delay to resupply $(37.5 \% ; P=0.041)$ were reasons for stock out of anti-TB commodities. Conclusion: Anti-TB drugs and LCs management performance of the HFs were found to be defective, which was confirmed by unsatisfactory data records, inconstant reports, deprived stock record accuracy, long lead time, high stock out rate, wastages, defective storage conditions, lack of training, and management support. Hence, respective organizations should improve their responsible activities to secure an uninterrupted supply of anti-TB drugs and LCs.

Keywords: anti-TB drugs, MDR-TB, laboratory commodities, health facilities, Ethiopia
Correspondence: Berhan Begashaw Yikna Tel +25I-919-365-179

Email berhan.uog1912@gmail.com

\section{Background}

Tuberculosis (TB) remains a major global health problem, with the majority of cases in developing countries. ${ }^{1}$ It is the leading cause of morbidity and mortality 
worldwide, accounting for about 10.4 million new cases and 1.5 million deaths in 2015.,3 According to recent estimates, Ethiopia stands 7th in the list of high TB burden countries. ${ }^{2,3}$ Inadequate TB treatment is an important factor that can contribute to the development of multi drugresistant (MDR)-TB strains and increase the mortality rate. ${ }^{2}$ In the absence of treatment with anti-TB drugs, about $70 \%$ of individuals with sputum smear-positive and $20 \%$ of people with culture-positive but smearnegative pulmonary TB died within 10 years of being diagnosed. ${ }^{4}$ Even if the annual TB incidence and mortality rate in Ethiopia is reducing, Ethiopia remains among the 30 countries reported with a high burden of TB and MDRTB for 2015-2020. ${ }^{5}$

Mostly, common causes of MDR-TB are man-made errors following an inadequate or poorly administered treatment regimen. The main factors causing inadequate treatment are unavailability of certain anti-TB drugs and laboratory commodities (LCs) used for diagnosis of TB due to stock-outs, delivery disruptions, poor storage conditions, and poor quality and regulation of medicines. ${ }^{2,6}$ Drug stock-out hinders access to effective treatment and achievement of treatment success targets. In 2013, shortages of anti-TB drugs were reported globally, even in the US. ${ }^{7}$ Other factors such as limited diagnostic and treatment facilities highly exacerbate the effect of MDRTB in the developing world including Ethiopia. ${ }^{8}$ Generally, poor commodity management practice has a great contribution for the spread of MDR-TB, ${ }^{2,6}$ and is a problem associated with poor data management and improper storage. It can result in poor medicine quality, theft, expiration, losses, and shortages. ${ }^{9}$ Therefore, such a shortage of commodities contributes to the spread of the TB epidemic. ${ }^{9}$ In TB control, stock-outs of drugs and diagnostic LCs are unacceptable. All anti-TB drugs and TB diagnostic LCs are essential for treatment and diagnosis and follow-up tests of TB patients, respectively. Therefore, they must be available throughout the time. ${ }^{10}$ Even though treatment with a 6-month course of first-line TB medicines cures almost $90 \%$ of TB cases, lack of access to appropriate medicines persist, especially MDRTB. ${ }^{11}$ Pediatric TB commodities access issues are more prominent in developing countries. ${ }^{11}$

Logistic management is the process of selection, quantification, procurement, inventory management, storage, distribution, and use, together with an effective logistic management information system (LMIS). ${ }^{9,12,13}$ In Ethiopia, all TB commodities selection, quantification, and procurement are done at the central Pharmaceutical Fund and Supply Agency (PFSA) level in collaboration with the National Tuberculosis Program/Federal Ministry of Health. Health facilities are responsible for inventory management, storage, and distribution of commodities from store to the TB clinics and laboratory units. ${ }^{14}$ Inventory management is the process to order, receive, store, issue, and then reorder anti-TB and LCs with the aim to secure a sustainable supply of these commodities. ${ }^{15}$ In the Ethiopian context; bin card (BC), internal facility report and resupply (IFRR) form, and report and requisition form (RRF) are the major stock records and inventory reports used for the commodity management. Facility TB clinics and laboratory units are required to submit an IFRR form and collect the anti-TB drugs and LCs from the facility store based on their schedule. The HF stores are required to fill the report and RRF every 2 months and submit it to their respective PFSA branches. Based on their report and request, PFSA branches refill facilities requests with the required pharmaceuticals. TB pharmaceuticals are stored only at central and branches of PFSA warehouses and HFs stores. HF stores are responsible to prepare distribution schedules for the $\mathrm{TB}$ clinics and laboratory units. $^{16}$

Deprived commodity management in HFs leads to the waste of financial resources, shortage of some medicines, or overage of others resulting in expiration and decline in the quality of patient care. In addition, it results in wrong decisions about order frequency and quantity, inaccurate stock records, and a lack of systematic performance monitoring. ${ }^{15}$ Therefore, to ensure an uninterrupted supply of anti-TB drugs and LCs, good inventory management is mandatory. Any imperfection interrupts service provision and the patients' appropriate use of TB drugs. ${ }^{9}$ Along all these processes, there are problems associated with the inventory management of anti-TB commodities such as non-availability, inaccurate and lack of updated BCs, unsatisfactory inventory management, and poor storage practice. ${ }^{16}$ To overcome problems associated with the inventory management system of the country, PFSA was established in 2007. So as to implement its mandate in the area of pharmaceuticals supply in an efficient and effective manner, an integrated pharmaceutical logistics system (IPLS) has been developed and implemented since 2010. ${ }^{14}$ Despite these and other ongoing efforts taken to improve the inventory management, evidence shows frequent stock depletions, shortages, and unsatisfactory management of such commodities at public HFs. Different studies done in 
Ethiopia show that there are intermittent supplies, shortage of anti-TB commodities, and poor utilization of recording and reporting logistic formats. ${ }^{17-19} \mathrm{~TB}$ is an expanding program which needs strong and supportive laboratory services. The capacity of the laboratory depends on the availability of the required LCs to perform these tests, which require multiple commodities like supplies, reagents, and equipment to be available simultaneously. However, the supply chain of LCs is a great challenge, especially in developing countries including Ethiopia. ${ }^{10,20}$

There are different factors that affect the inventory management performance at HFs. According to research done in Ethiopia in 2014, data management, government support, and pharmacy professionals skills affect the supply chain management (SCM) performance. ${ }^{15}$ Another study conducted in 2016 in Ethiopia also shows that the scarcity and lack of expertise in SCM, lack of commitment and motivation, gap in leadership, knowledge and skill, weak integration of different stakeholders, poor warehouse design, and transport facilities are factors for the inventory management performance. ${ }^{21}$ Assessment of IPLS in Ethiopia in 2015 also shows supportive supervision, trained personnel, and coordination with the distribution system were some of the factors contributing to inventory management performance. ${ }^{16}$

Studies that have assessed the SCM of anti-TB commodities in the city administration are limited. Our study is, therefore, needed to assess anti-TB commodities inventory management performance and challenges associated with it in public HFs of Dire Dawa city administration, east Ethiopia. Thus, a need arises to conduct this research in order to determine the extent of the problem of inventory management of anti-TB drugs and LCs. Findings from this study will help program managers, supply chain officers, donors, stakeholders, and policy-makers to know the problems and develop strategic plans to solve and bridge the gaps that will minimize these problems so as to ensure a sustainable and uninterrupted supply of antiTB commodities in the country. In addition to this, it will be useful to HFs managers to strengthen their management support and follow-up by planning different activities.

\section{Methods and Materials Study Area and Period}

Dire Dawa city administration is located in the eastern part of Ethiopia (Figure 1). It is $515 \mathrm{~km}$ from Addis Ababa and covers an area of $1,547 \mathrm{~km}^{2}$, with a total population of
427,000. Currently, there are 14 health centers, one general and one primary hospital which are owned by the government, and four private hospitals. In addition, there are six primary clinics, 24 medium clinics, one higher clinic, nine medium dental clinics, one specialized pediatric clinic, one public diagnostic laboratory, and one international basic diagnostic laboratory. ${ }^{22}$ The study was conducted between the time periods of December 2018 and May 2019.

\section{Study Design}

A facility-based cross-sectional study design was conducted by using a quantitative and qualitative method. For the quantitative part, indicators were used to measure the inventory management performance. All public HFs in Dire Dawa city administration that provide TB diagnosis and treatment services, all anti-TB drugs, all LCs used for diagnosis of TB, all drugs used for MDR-TB treatment, selected logistic data records and key informants (KIs) from HFs, supply chain officers (pharmacy coordinators), store managers, and laboratory unit coordinators were the study population. All public HFs that were providing TB and MDR-TB services and health professionals with work experience of more than 6 months were included in this study.

\section{Sample Size Determination and Sampling Technique}

The study included all public HFs in the city. Logistics indicators assessment tools (LIATs), a quantitative data collection instrument developed by USAID/DELIVER, was used. $^{23,24}$ The most recent RRF reports were used with a total of 16 RRFs (one from each HF). A total of 125 BCs from all HFs were assessed (111 BCs for anti-TB drugs and 14 for LCs used for TB diagnosis). The most recent IFRR reports (6 months back from day of data collection) were used. Seven first line anti-TB drugs which were used to prevent and cure TB, eight second line drugs which were used for MDR-TB treatment, and 14 different kinds of laboratory reagents and supplies which were used to diagnose TB were used. Key informants such as pharmacy coordinators, laboratory unit coordinators, and pharmacy store managers were selected from public HFs purposively (File S1).

\section{Study Variables}

Logistic management information system (LMIS) performance, stock out rate, storage condition and wastage of 


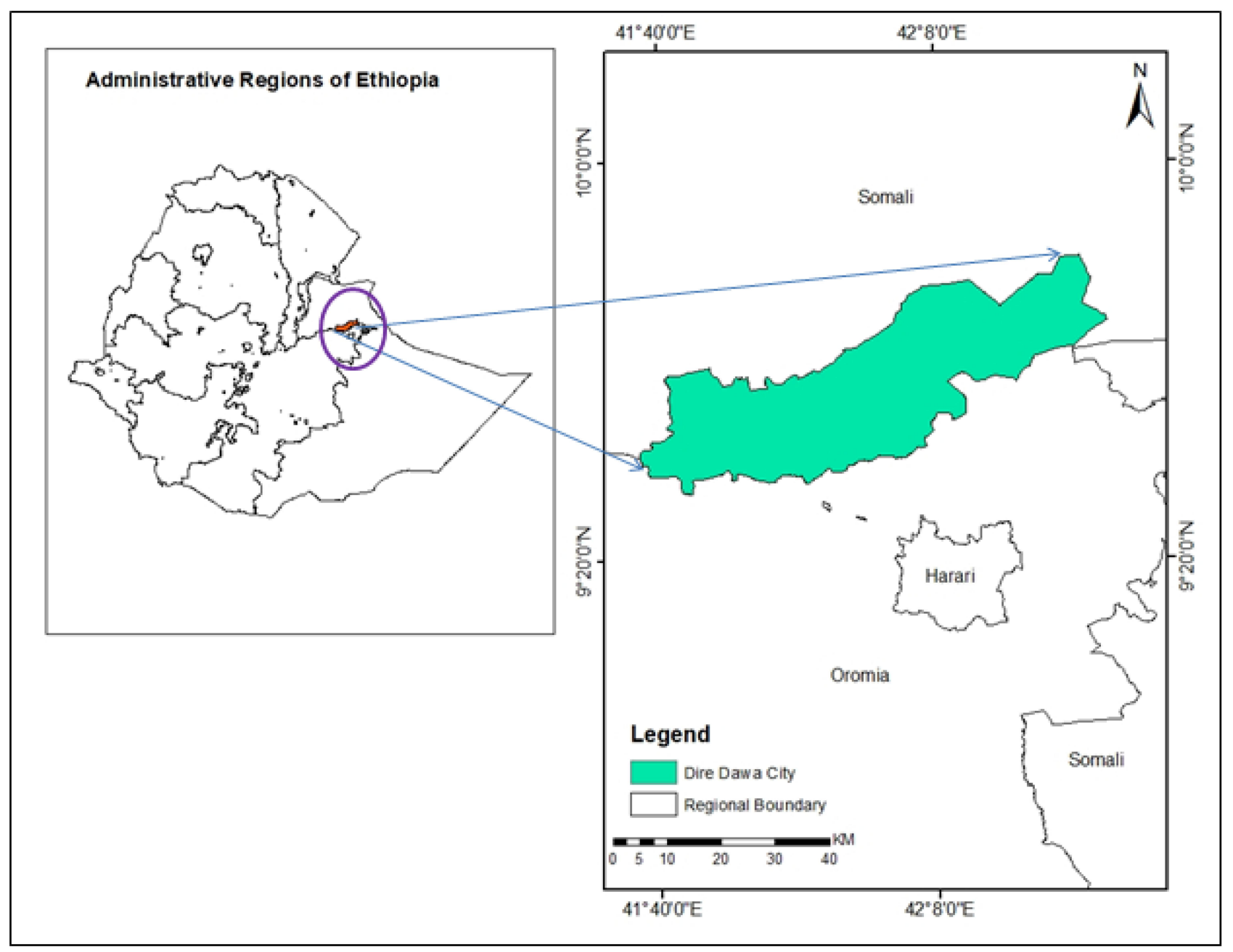

Figure I Map of the study area; Dire Dawa city administration.

commodities were the dependent variables, whereas organizational and personal support, logistic record system, wastage, stock out, and storage condition related factors were the independent variables, as indicated in Figure 2.

\section{Data Collection Procedures}

A data collection instrument was developed from LIATs $^{23,24}$ to collect the necessary data. In addition, a review of relevant documents with a maximum of 6-month duration, structured observation using checklists, and physical counts of the products were done. The data was collected by trained pharmacy professionals under close supervision. To assess the challenges associated with inventory management, open-ended and closed semistructured questionnaires and face-to-face interviews with
KIs (pharmacy coordinators, store managers, and laboratory coordinators) with some probes were used for qualitative data collection.

\section{Data Processing and Analysis}

The quantitative data were checked for completeness and then entered into Epi-Data version 3.1 and transported to SPSS (IBM Corporation, Armonk, NY, USA) version 20 to analyze the result. Descriptive statistics such as frequencies, mean, percentage, and statement were used to represent data. In addition, advanced statics such as chi-square were used to test the presence of association between the variables and $P$-value $(P<0.05)$ was considered as an association between variables. The qualitative data was analyzed based on coding thematically. 


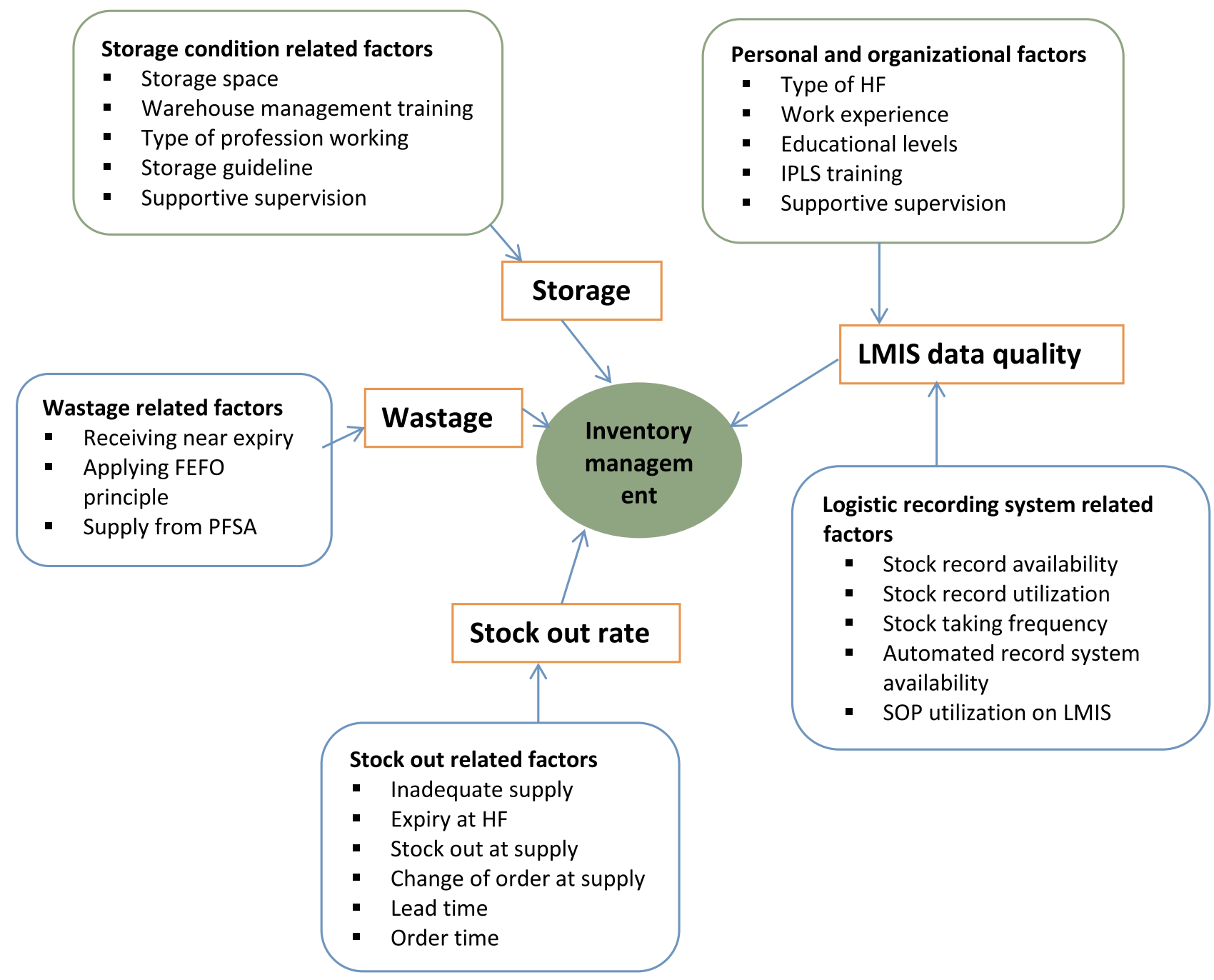

Figure 2 Conceptual framework of the study.

\section{Data Quality Assurance}

Training was given to data collectors and a pre-test was carried out prior to data collection to assess the clarity and consistency of the data collection tool. We discussed with the data collectors on regular activities and reviewed the collected data for completeness.

\section{Ethical Considerations}

Ethical approval was obtained from the Ethics Review Board of Institute of Health, Jimma University (Ref.No. IHRPGC/797/327). In addition, permission to conduct the research was obtained from the city administration health bureau and the HFs. Both written and verbal consent from respondents was obtained prior to conducting the study, and enough information was given about the purpose of the study. Participants were assured about confidentiality.
Personal identifiers were not used, to ensure the anonymity of respondents.

\section{Results}

\section{Socio-Demographic Characteristics of Health Facilities}

Among a total of $16 \mathrm{HFs}$, two were hospitals and 14 were health centers. Basic TB treatment services were given in all HFs, whereas MDR-TB treatment service was given in one general hospital. From the $16 \mathrm{HFs}, 11$ (68.8\%) of them were using a florescence microscope. Among 72 pharmacy professionals, $42(58.3 \%)$ had a pharmacy diploma, followed by 27 (37.5\%) pharmacy degree holders. Of the 16 store managers working in the store, $14(87.5 \%)$ of them were pharmacy technicians. The majority of the staff $(69 ; 95.8 \%)$ had taken IPLS training; however, none of them had taken 
training related to warehouse management, laboratory commodity management (LCM), or health commodity management information system (HCMIS) software. All store managers were responsible to manage anti-TB drugs and laboratory supplies. None of the store managers were responsible for managing laboratory reagents (Table 1).

\section{LMIS Performance of Anti-TB}

\section{Commodities}

\section{Utilization of LMIS Tools, Stock Record Availability,} Updating Practices, and Accuracy

All HFs were using RRF, IFRR, and BC. However, only four (25\%) of the HFs' TB clinics and three (18.8\%) of the

Table I Sociodemographic Characteristics of Public HFs of Dire Dawa City Administration, May 2019

\begin{tabular}{|c|c|c|c|}
\hline \multicolumn{3}{|l|}{ Variables } & \multirow{2}{*}{$\begin{array}{l}\begin{array}{l}\text { Frequency } \\
\text { (\%) }\end{array} \\
11(68.8) \\
5(31.3) \\
3(18.8)\end{array}$} \\
\hline Health facilities using & \multicolumn{2}{|c|}{$\begin{array}{l}\text { FM microscope } \\
\text { ZN microscope } \\
\text { Gene Xpert machine }\end{array}$} & \\
\hline Health facilities given & \multicolumn{2}{|c|}{$\begin{array}{l}\text { Basic anti-TB service } \\
\text { MDR-TB service }\end{array}$} & $\begin{array}{l}16(100) \\
1(6.3)\end{array}$ \\
\hline $\begin{array}{l}\text { Professions under } \\
\text { pharmacy units }\end{array}$ & \multicolumn{2}{|c|}{$\begin{array}{l}\text { MSc (clinical pharmacy) } \\
\text { Pharmacist } \\
\text { pharmacy technician }\end{array}$} & $\begin{array}{l}3(4.2) \\
27(37.5) \\
42(58.3)\end{array}$ \\
\hline $\begin{array}{l}\text { Professional qualification } \\
\text { under pharmacy stores }\end{array}$ & \multicolumn{2}{|c|}{$\begin{array}{l}\text { Pharmacist } \\
\text { Pharmacy technician }\end{array}$} & $\begin{array}{l}2(12.5) \\
14(87.5)\end{array}$ \\
\hline $\begin{array}{l}\text { Store managers } \\
\text { responsible for managing }\end{array}$ & \multicolumn{2}{|c|}{$\begin{array}{l}\text { Anti-TB drugs } \\
\text { Laboratory supplies } \\
\text { Laboratory reagents }\end{array}$} & $\begin{array}{l}16(100) \\
16(100) \\
0(0)\end{array}$ \\
\hline $\begin{array}{l}\text { Service year (store } \\
\text { manager and pharmacy } \\
\text { head) }\end{array}$ & \multicolumn{2}{|c|}{$\begin{array}{l}6 \text { months }-1 \text { year } \\
1-3 \text { year } \\
>3 \text { years }\end{array}$} & $\begin{array}{l}1(3.1) \\
10(31.3) \\
21(65.6)\end{array}$ \\
\hline $\begin{array}{l}\text { Delivery modality from } \\
\text { PFSA }\end{array}$ & $\begin{array}{l}\text { Direct } \\
\text { Indirect }\end{array}$ & & $\begin{array}{l}16(100) \\
0(0)\end{array}$ \\
\hline \multirow[t]{4}{*}{$\begin{array}{l}\text { Training taken by store } \\
\text { manager }\end{array}$} & IPLS & $\begin{array}{l}\text { Trained } \\
\text { Not trained }\end{array}$ & $\begin{array}{l}14(87.5) \\
2(12.5)\end{array}$ \\
\hline & LCM & $\begin{array}{l}\text { Trained } \\
\text { Not trained }\end{array}$ & $\begin{array}{l}0(0) \\
16(100)\end{array}$ \\
\hline & $\begin{array}{l}\text { Warehouse } \\
\text { management }\end{array}$ & $\begin{array}{l}\text { Trained } \\
\text { Not trained }\end{array}$ & $\begin{array}{l}0(0) \\
16(100)\end{array}$ \\
\hline & HCMIS & $\begin{array}{l}\text { Trained } \\
\text { Not trained }\end{array}$ & $\begin{array}{l}0(0) \\
16(100)\end{array}$ \\
\hline
\end{tabular}

Abbreviations: FM, florescence microscope; ZN, Ziehl-Neelsen; IPLS, integrated pharmaceutical logistic system; LCM, laboratory commodity management; HCMIS, health commodity management information system. laboratory units used $\mathrm{BC}$ for stock control. Thirteen (81.5\%) HFs had automated recoding systems, which is called HCMIS. All TB clinics and laboratory units used IFRR. All first-line anti-TB drugs were recorded on the BCs in all HFs store except for ethambutol $400 \mathrm{mg}$, which was recorded on BC only in nine (56.3\%) HFs. Among 105 available BCs for first-line anti-TB drugs, 42 (40\%) were not updated. The average BC accuracy rate was found to be $77.2 \%$, with the range of $62.5 \%$ for fixed dose combinations (FDCs) of rifampicin (R), isoniazid $(\mathrm{H})$, pyrazinamide $(\mathrm{Z})$, and ethambutol (E) (RHZE kit) to 93.7\% for ethambutol $100 \mathrm{mg}$ (Table 2). Among the assessed second line medicines for MDR-TB treatment service, six $(75 \%)$ of the drugs were documented on the $\mathrm{BCs}$ in the store and, of these, five $(62.5 \%)$ of them were updated. Only seven (43.8\%) and six (37.5\%) HFs used BCs for wooden applicator sticks without cotton and frosted end microscope slide, respectively. Almost none of the LCs [sputum cup, filter paper, lens cleaning solution, immersion oil, lens paper, Xpert Mycobacterium tuberculosis/rifampicin test (Xpert MTB/RIF) cartridges and falcon tube] had been $\mathrm{BC}$ in the main pharmacy store. Thus, it is less important to show the accuracy rate and updating practice for these supplies.

\section{Report and Requisition Form (RRF) Data Accuracy and Completeness}

None of the HF was $100 \%$ accurate for all types of products. On average, $44.3 \% \mathrm{HFs}$ were not accurate for RRF report (Table 3). Among eight MDR-TB drugs which were managed only in one hospital; cycloserine $250 \mathrm{mg}$, pyrazinamide $400 \mathrm{mg}$, para-aminosalicylic acid (PAS) $4 \mathrm{mg}$, and moxifloxacilline $400 \mathrm{mg}$ were accurately filled out on the reporting form; however, the rest of the drugs, such as capreomycin $1 \mathrm{gm}$, prothionamide $250 \mathrm{mg}$, levofloxacilline $250 \mathrm{mg}$, and kanamycin $1 \mathrm{gm}$, were not accurately filled out on the RRF. Of the assessed $16 \mathrm{HFs}$, half of them had a standard operating procedure (SOP) for LMIS. RRF accuracy had a significant association with the presence of LMIS-SOP and frequency of stock taking practice which was revealed by Fishers exact test $(P=0.019)$ and likelihood ratio $(P=0.046)$, respectively. None of the HFs had a complete RRF report in which all columns were filled. Of the reviewed RRFs, none of the HFs had filled stock on hand (SOH) at the dispensing unit (DU) for all products. Three of the reports had no loss/ adjustment and days out of stock filled for all products. None of the TB laboratory diagnostic supplies used for 
Table 2 Bin Card Availability, Updating Practice and Accuracy for First Line Anti-TB Commodities at HFs of Dire Dawa City Administration, May, 2019

\begin{tabular}{|c|c|c|c|c|c|c|}
\hline \multirow[t]{2}{*}{ List of Products } & \multicolumn{2}{|c|}{ Bin Card Availability } & \multicolumn{2}{|c|}{ Bin Card Updating Practice } & \multicolumn{2}{|c|}{ Bin Card Accuracy } \\
\hline & $\begin{array}{l}\text { Available, } \\
\text { n (\%) }\end{array}$ & $\begin{array}{l}\text { Not Available, } \\
\text { n (\%) }\end{array}$ & $\begin{array}{l}\text { Updated, } \\
\text { n (\%) }\end{array}$ & $\begin{array}{l}\text { Not Updated, } \\
\text { n (\%) }\end{array}$ & $\begin{array}{l}\text { Accurate, } \\
\text { n (\%) }\end{array}$ & $\begin{array}{l}\text { Inaccurate, } \\
\text { n (\%) }\end{array}$ \\
\hline $\mathrm{E}-400 \mathrm{mg}$ & $9(56.3)$ & 7 (43.7) & $3(33.4)$ & $6(66.6)$ & $7(77.8)$ & $2(22.2)$ \\
\hline $\mathrm{E}-100 \mathrm{mg}$ & $16(100)$ & $0(0)$ & $9(56.3)$ & $7(43.7)$ & $15(93.7)$ & $\mathrm{I}(6.3)$ \\
\hline INH-I00 mg & $16(100)$ & $0(0)$ & $10(62.5)$ & $6(37.5)$ & $13(8 \mid .3)$ & $3(18.7$ \\
\hline INH-300 mg & $16(100)$ & $0(0)$ & II (68.7) & $5(3 \mid .3)$ & $12(75)$ & $4(25)$ \\
\hline RH-75/50 mg & $16(100)$ & $0(0)$ & $12(75)$ & $4(25)$ & II (68.7) & $5(31.3)$ \\
\hline RHZ-75/50/I50 mg & $16(100)$ & $0(0)$ & $9(56.3)$ & $7(43.7)$ & $13(8 \mid .3)$ & $3(18.7)$ \\
\hline RHZE/RH-kit & $16(100)$ & $0(0)$ & $9(56.3)$ & $7(43.7)$ & $10(62.5)$ & $6(37.5)$ \\
\hline Average & $15(93.8)$ & I (6.2) & $9(58.4)$ & $6(4 \mid .6)$ & $12(77.2)$ & $4(22.8)$ \\
\hline
\end{tabular}

Abbreviations: INH, isoniazid; RHZE, rifampicin, isoniazid, pyrazinamide, ethambutol.

acid-fast bacillus (AFB) staining procedure were reported to PFSA in the reviewed report.

Internal Facility Requisition and Report (IFRR) Reporting Rate and Completeness

All health facilities for TB and laboratory DUs reported their IFRR every 2 weeks, except one HFTB clinic which submitted every month to the store. Although the reporting rate and completeness of IFRR at all HFs were expected to be $100 \%$, the reporting rate was $69.4 \%$ and $66.7 \%$ for TB clinic units and laboratory DUs, respectively. Among actually submitted IFRR reports, $85.3 \%$ of TB clinic units and $86 \%$ laboratory DUs IFRR were complete, which contained the beginning balance, stock on hand, quantity received, and loss/adjustment. The rest missed any of the four essential data.

Table 3 RRF Accuracy Rate for Anti-TB Drugs at Health Facilities of Dire Dawa City Administration, May 2019

\begin{tabular}{|l|l|l|l|}
\hline Products & n (HF) & $\begin{array}{l}\text { Accurate } \\
\text { RRF Report, } \\
\text { n (\%) }\end{array}$ & $\begin{array}{l}\text { Inaccurate } \\
\text { RRF Report, } \\
\text { n (\%) }\end{array}$ \\
\hline E-400 mg & 9 & $3(33.3)$ & $6(66.7)$ \\
E-I00 mg & 16 & $9(56.3)$ & $7(43.8)$ \\
INH-100 mg & 16 & $8(50.0)$ & $8(50)$ \\
INH-300 mg & 16 & $8(50.0)$ & $8(50)$ \\
RH-75/50 mg & 16 & $9(56.3)$ & $7(43.8)$ \\
RHZ-75/50/I50 mg & 16 & $11(68.8)$ & $5(31.3)$ \\
RHZE/RH kit & 16 & $12(75.0)$ & $4(25)$ \\
\hline Average & & $(55.7)$ & $(44.3)$ \\
\hline
\end{tabular}

Abbreviations: RRF, report and requisition form; $\mathrm{HF}$, health facility; $\mathrm{INH}$, isoniazid RHZE, rifampicin, isoniazid, pyrazinamide, ethambutol.

\section{Emergency Order}

Half of the HFs placed at least one emergency order in the last 6 months for pediatric fixed dose commodities (RHZ and $\mathrm{RH}$ ), ethambutol $100 \mathrm{mg}$, falcon tube, and cartridge.

\section{Inventory Control System and Stock Status of Anti-TB Commodities Supervision, Inventory Taking Practice, and Lead Time}

Eleven (81.3\%) HFs had received supervision within the last month. Five $(31.3 \%)$ of them received it in the past 1-3 months. Five (31.3\%), four (25\%), four $(25 \%)$, and two $(12.5 \%)$ of the HFs had been taking inventory quarterly, bimonthly, annually, and at any time during issuing, respectively. The rest $(6.2 \%)$ of them took it monthly. In addition to this, the lead time by the store managers was assessed. Based on this, $10 \mathrm{HFs}$ perceived that the lead time for the last order was 3 weeks to 1 month from the order date, while four HFs perceived 1-2 months to receive their order.

\section{Order Fill Rate by Products}

Ten $(62.5 \%)$ HFs had an order fill rate of more than $80 \%$ of products they ordered. When disaggregated by product, $15(93.8 \%)$ HFs received the quantity ordered for each isoniazid (INH) $100 \mathrm{mg}$ and $300 \mathrm{mg}$. One HF received insufficient quantity ordered for ethambutol $100 \mathrm{mg}$, INH $100 \mathrm{mg}$ and $300 \mathrm{mg}$ (Table 4). Of the requested second line anti-TB drugs, all were supplied by PFSA as per the requested quantity. Even if laboratory supplies are expected to be reported with drugs every 2 months, none of the HFs reported to PFSA for the last reporting period. 
Table 4 Order Fill Rate of Anti-TB Drugs at Health Facilities of Dire Dawa City Administration, May 2019

\begin{tabular}{|c|c|c|c|}
\hline $\begin{array}{l}\text { Anti-TB } \\
\text { Commodities }\end{array}$ & $\begin{array}{l}\text { HFs } \\
\text { Received } \\
\text { Quantity } \\
\text { of } \\
\text { Products } \\
\text { Ordered, } \\
\text { n (\%) }\end{array}$ & $\begin{array}{l}\text { HFs Received } \\
\text { Insufficient } \\
\text { Quantity of } \\
\text { Products } \\
\text { Ordered, n (\%) }\end{array}$ & $\begin{array}{l}\text { HFs } \\
\text { Received } \\
\text { More } \\
\text { Quantity of } \\
\text { Products } \\
\text { Ordered, } \\
\text { n (\%) }\end{array}$ \\
\hline $\mathrm{E}-400 \mathrm{mg}$ & $13(81.3)$ & $3(18.8)$ & $0(0)$ \\
\hline $\mathrm{E}-100 \mathrm{mg}$ & $13(81.3)$ & I (6.2) & $2(12.5)$ \\
\hline $\mathrm{INH}-100 \mathrm{mg}$ & $15(93.8)$ & I (6.2) & $0(0)$ \\
\hline $\mathrm{INH}-300 \mathrm{mg}$ & $15(93.8)$ & I (6.2) & $0(0)$ \\
\hline $\mathrm{RH}-75+50 \mathrm{mg}$ & II (68.7) & $2(12.5)$ & $3(18.8)$ \\
\hline RHZ-75+50+150mg & $10(62.5)$ & $I(6.2)$ & $5(31.2)$ \\
\hline RHZE/RH kit & $12(75)$ & $0(0)$ & $4(25)$ \\
\hline Average & (79.5) & (8) & (I2.5) \\
\hline
\end{tabular}

Abbreviations: $\mathrm{HF}$, health facility; INH, isoniazid; RHZE, rifampicin, isoniazid, pyrazinamide, ethambutol.

\section{Stock Status by Commodity Type}

Only four (25\%) HFs had stock within the minimummaximum stock levels for each of ethambutol $400 \mathrm{mg}$, $100 \mathrm{mg}$, and INH $300 \mathrm{mg}$. Three (18.8\%) HFs had below the minimum stock level for INH $100 \mathrm{mg}$, RH 75/50 mg, and RHZE/RH kit. Eleven (68.8\%) HFs had above the maximum stock level for ethambutol $100 \mathrm{mg}$ (Table 5). For second line drugs and laboratory reagents, it was impossible to measure using this indicator because inventory control was not merely based on consumption. It was based on consumption, the number of patients available in

Table 5 Stock Status of First Line Anti-TB Drugs at Health Facilities of Dire Dawa City Administration, May 2019

\begin{tabular}{|l|l|l|l|}
\hline Commodities & $\begin{array}{l}\text { HFs with } \\
\text { Less Than } \\
\text { the } \\
\text { Minimum } \\
\text { Stock Level, } \\
\mathbf{n}(\%)\end{array}$ & $\begin{array}{l}\text { HFs with } \\
\text { Higher Than } \\
\text { the } \\
\text { Maximum } \\
\text { Stock Level, } \\
\text { n (\%) }\end{array}$ & $\begin{array}{l}\text { HFs within } \\
\text { the } \\
\text { Minimum } \\
\text { Maximum } \\
\text { Stock Level, } \\
\text { n (\%) }\end{array}$ \\
\hline $\begin{array}{l}\text { E-400 mg } \\
\text { E-I00 mg }\end{array}$ & $9(56.3)$ & $3(18.8)$ & $4(25)$ \\
INH-100 mg & $1(6.3)$ & $11(68.8)$ & $4(25)$ \\
INH-300 mg & $2(18.8)$ & II (68.8) & $2(12.5)$ \\
RH-75+50 mg & $3(12.5)$ & $10(62.5)$ & $4(25)$ \\
RHZ-75+50+I50 mg & $6(37.5)$ & $10(62.5)$ & $3(18.8)$ \\
RHZE/RH kit & $3(18.8)$ & $7(43.8)$ & $3(18.8)$ \\
\hline Average & $(24.1)$ & $(62.5)$ & $3(18.8)$ \\
\hline
\end{tabular}

Abbreviations: HFs, health facilities; INH, isoniazid; RHZE, rifampicin, isoniazid, pyrazinamide, ethambutol. the quarter, and the number of new patients to be enrolled (morbidity data). Laboratory reagents have no placed maximum-minimum stock level at which orders need to be placed.

\section{Storage Conditions of Health Facilities}

The storage condition of the HFs was assessed based on visual inspection using indicators as per good pharmacy practice standards for storage conditions indicated in LIATs. ${ }^{23}$ Based on this, the findings of our research showed that only eight $(50 \%)$ of the study facilities have fulfilled good storage conditions ( $\geq 80 \%$ positive response to the indicators). When disaggregated by facility level, the primary and general hospital fulfilled $58.3 \%$ and $75 \%$, respectively, whereas the remaining HFs fulfillment range was from $58.3-100 \%$. In addition to this, $50 \%$ HFs had storage guidelines. All of the surveyed health facilities were visually free from harmful insects and rodents, and protected from direct sunlight and water and humidity. However, only nine $(56.3 \%)$ HFs had relatively sufficient space for medicines storage and free space for future expansion (Table 6). Fisher's exact test revealed that the storage conditions of medicines had a significant association with the presence of storage guidelines in the store $(P=0.041)$.

\section{Value of Unusable Anti-TB Commodities}

The amount of medicines wasted within the last 9 months (July 2018 to March 2019) that means starting from the new budget year up to data collection time were assessed to calculate the value of wastage of medicines. Wastages were calculated based on the medicines unit price obtained from PFSA. Based on this, a total of 84,275.04 Ethiopian birr was lost because of wastage and expiry of medicine from all HFs. The majority, kanamycin 1 gm, RH-60/30 mg, and RHZ-60/ $30 / 150 \mathrm{mg}$ accounted for 29,140.00, 20,769.31, and 13,073.13 birr, respectively. The remaining PAS $4 \mathrm{mg}$ and ethambutol $100 \mathrm{mg}$ accounted for 9,600.00 and 1,612.60 birr, respectively. Regimen change (56.3\%), receiving near expiry (56.3\%), fail to practice first expired-first out (FEFO) (50\%) and over supply of medicine from PFSA (43.8\%) were reported as the most common reasons for wastage. Receiving near expiry, failure to practice FEFO and regimen change had significant associations with wastage of products $(P<0.05)$, which were revealed by Fisher's exact test.

\section{Stock Out of Anti-TB Commodities}

Based on our study, half of the HFs had stock on hand continuously available for more than $80 \%$ of products they 
Table 6 Health Facilities Adherence to Good Pharmacy Practice Standards in Health Facilities of Dire Dawa City Administration, May 2019

\begin{tabular}{|c|c|c|c|}
\hline Descriptions & Yes & No & $\begin{array}{l}\text { Adherence } \\
\%\end{array}$ \\
\hline $\begin{array}{l}\text { Products are arranged on shelves with arrows pointing up and identification labels and expiry dates and/or } \\
\text { manufacturing dates are visible }\end{array}$ & 12 & 4 & 75 \\
\hline $\begin{array}{l}\text { Products are stored and organized in a manner accessible for first-to-expire, first-out (FEFO) counting and } \\
\text { management }\end{array}$ & 7 & 9 & 43.8 \\
\hline $\begin{array}{l}\text { Cartons and products are in good condition, not crushed due to mishandling. If cartons are open, determine if } \\
\text { products are wet or cracked due to heat/radiation (fluorescent lights in the case of condoms, cartons right side up } \\
\text { for Depo-Provera) }\end{array}$ & 15 & 1 & 93.8 \\
\hline $\begin{array}{l}\text { The facility makes it a practice to separate damaged and/or expired products from usable products and removes } \\
\text { them from the inventory }\end{array}$ & 15 & 1 & 93.8 \\
\hline Products are protected from direct sunlight & 16 & 0 & 100 \\
\hline Cartons and products are protected from water and humidity & 16 & 0 & 100 \\
\hline Storage area is visually free from harmful insects and rodents & 16 & 0 & 100 \\
\hline $\begin{array}{l}\text { Storage area is secured with a lock and key, but is accessible during normal working hours; access is limited to } \\
\text { authorized personnel }\end{array}$ & 14 & 2 & 87.5 \\
\hline Products are stored at the appropriate temperature according to product temperature specifications & 9 & 7 & 56.3 \\
\hline Roof is maintained in good condition to avoid sunlight and water penetration & 15 & 1 & 93.3 \\
\hline Storeroom is maintained in good condition (clean, all trash removed, sturdy shelves, organized boxes) & 10 & 6 & 62.5 \\
\hline The current space and organization is sufficient for existing products and reasonable expansion & 9 & 7 & 56.3 \\
\hline
\end{tabular}

manage for the past 6 months, which could be considered as good. When disaggregated by product type, $50 \% \mathrm{HFs}$ were stocked out for INH $300 \mathrm{mg}$ and RHZ in the past 6 months, with mean stock out durations of 10.8 and 18.9 days, respectively. Five (31.3\%) HFs were stocked out for RH with a mean stock out duration of 2.81 days. RHZE was not stocked out in all of the HFs within 6 months. In addition, six (66.7\%) HFs had stock out for ethambutol $400 \mathrm{mg}$, with a mean stock out duration of 70.5 days (Table 7).

MDR-TB treatment service was given at one general hospital in the city administration. Of the eight second-line anti-TB drugs, only PAS 4 gm was stocked out on the day of visit and for 15 days in the past 6 months. On average, $12.5 \%$ of drugs were stocked out. Ziehl-Neelsen and Fluorescence microscopes (ZN and FM) were used for diagnosing TB. These microscopes use different type of supplies and reagents. Because most of the HFs did not use BCs for these supplies and reagents, it was impossible to know
Table 7 Percentage of Health Facilities That Experienced a Stock Out for First Line Drugs on the Day of Visit and in the Past 6 Months of Dire Dawa City Administration, May 2019

\begin{tabular}{|c|c|c|c|c|}
\hline Commodities & n (HF) & $\begin{array}{l}\text { HFs } \\
\text { Stock } \\
\text { Out } \\
\text { on the } \\
\text { Day of } \\
\text { Visit, } \\
\text { n (\%) }\end{array}$ & $\begin{array}{l}\text { HFs Stock } \\
\text { Out any } \\
\text { Time in } \\
\text { the Past } 6 \\
\text { Months, } \\
\text { n (\%) }\end{array}$ & $\begin{array}{l}\text { Mean No. } \\
\text { of Days } \\
\text { [Range] of } \\
\text { Stock Outs } \\
\text { in the Past } \\
6 \text { Months }\end{array}$ \\
\hline $\mathrm{E}-400 \mathrm{mg}$ & 16 & $9(56.3)$ & $6(66.7)$ & 70.5 [0-180] \\
\hline $\mathrm{E}-100 \mathrm{mg}$ & 16 & $0(0)$ & $2(12.5)$ & 2.1 [0-23] \\
\hline $\mathrm{INH}-100 \mathrm{mg}$ & 16 & I (6.3) & $3(18.8)$ & I5.I [0-180] \\
\hline $\mathrm{INH}-300 \mathrm{mg}$ & 16 & I (6.3) & $8(50)$ & $10.8[0-88]$ \\
\hline $\mathrm{RH}-75+50 \mathrm{mg}$ & 16 & $2(12.5)$ & $5(31.3)$ & $2.8[0-13]$ \\
\hline $\begin{array}{l}\text { RHZ-75+50 } \\
+150 \mathrm{mg}\end{array}$ & 16 & $7(43.8)$ & $8(50)$ & $18.9[0-120]$ \\
\hline RHZE/RH-kit & 16 & $0(0)$ & $0(0)$ & $0[0-0]$ \\
\hline Average & & $(17.9)$ & (32.8) & $17.2[0-180]$ \\
\hline
\end{tabular}

Abbreviations: HF, health facility; INH, isoniazid; RHZE, rifampicin, isoniazid, pyrazinamide, ethambutol. 
whether a stock out occurred in the past 6 months or not. Therefore, only stock out on the day of visit was assessed and, based on this, all HFs using a ZN microscope was stocked out for lens cleaning solution and lens paper. Filter paper, sputum cup, and wooden applicator stick without cotton were out of stock in $10(62.6 \%)$, six $(37.5 \%)$, and two $(12.5 \%)$ of the HFs, respectively. All HFs were not stocked out for frosted end microscope slides, $1 \%$ auramine $\mathrm{O}$ in alcohol, and phenolic solution for auramine. Three HFs that used gene Xpert machine were not stocked out for Xpert MTB/RIF cartridges and falcon tube (Table 8).

\section{Reasons for Stock Out}

Among the reasons for stock out of anti-TB commodities in the HFs, regimen change $(11 ; 68.8 \%)$ and low demand $(9 ; 56.3 \%)$ were the most common reasons, as indicated in Figure 3. The stock out of medicines had significant associations with delay from PFSA $(P=0.041)$, low demand ( $P=0.041)$, and regimen change $(P=0.026)$, which were revealed by Fisher's exact test.

\section{Challenges in Inventory Management Performance of Anti-TB Commodities}

The qualitative data was collected through an in-depth faceto-face interview of KIs. The data was analyzed thematically by categorizing into four main thematic areas such as human resource, capacity building and information,

Table 8 Percentage of Health Facilities Stocked Out for Laboratory Supplies and Reagents of Dire Dawa City Administration, May 2019

\begin{tabular}{|l|l|l|}
\hline $\begin{array}{l}\text { Laboratory Supplies and } \\
\text { Reagents }\end{array}$ & $\mathbf{n}$ (HFs) & $\begin{array}{l}\text { Stock Out on } \\
\text { the Day of } \\
\text { Visit, } \mathbf{n}(\%)\end{array}$ \\
\hline Frosted end microscope slide & 16 & $0(0)$ \\
Wooden applicator without cotton & 16 & $2(12.5)$ \\
Sputum cup & 16 & $6(37.5)$ \\
Filter paper & 16 & $10(62.6)$ \\
Lens cleaning solution & 5 & $5(100)$ \\
Lens paper & 5 & $5(100)$ \\
I\% basic carbol fuchsin & 5 & $2(40)$ \\
Oil immersion & 5 & $2(40)$ \\
I\% Auramine O in alcohol & 11 & $0(0)$ \\
Phenolic solution for Auramine & 11 & $0(0)$ \\
$0.5 \%$ or 3\% acid alcohol solution & 16 & $1(6.3)$ \\
$0.3 \%$ or 0.I\% methylene blue & 16 & $1(6.3)$ \\
Xpert MTB/RIF cartridges & 3 & $0(0)$ \\
Falcon tube & 3 & $0(0)$ \\
\hline
\end{tabular}

Abbreviations: HFs, health facilities; MTB/RIF, Mycobacterium tuberculosis/ rifampicin.

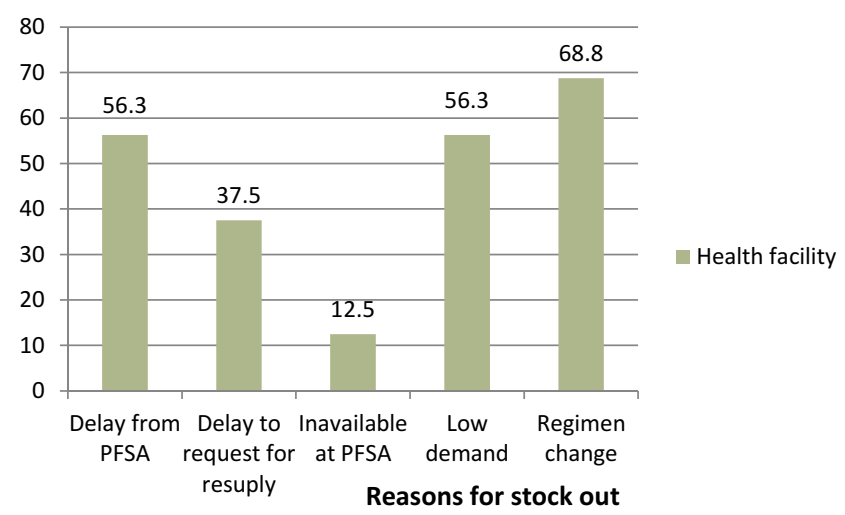

Figure 3 Reasons for stock-out of anti-TB commodities at health facilities of Dire Dawa city administration, May 2019.

management support, and inventory management-related challenges.

\section{Challenges Related to Human Resources}

Most of the interviewees (store managers) mentioned that involvement of the store managers in dispensing practice and night duty program increased the burden on the store managers which was a challenge to keep logistic data accuracy and quality. For example, one of the respondents clearly stated that he had told his immediate boss he resigned his store keeper position frequently; however, his immediate boss confirmed that no one could replace him in the aforementioned position. Another respondent confirmed that while he was working in the dispensary, the store would be closed. For this reason, patients could not access necessary drugs even if the drugs were abundantly stored. In addition, another most prominent stumbling block mentioned by one of the KIs in this study was the absence of a permanently employed daily laborer for loading and unloading different commodities upon the arrival of the necessary commodities. Furthermore, some respondents assured that store managers were obliged to unload and arrange commodities in the store which is time taking and tiresome to complete all logistic records. Finally, another KI respondent claimed that the reason to develop negative attitude toward his profession was working and being fully engaged as a daily laborer without any sort of additional incentive.

\section{Challenges Related to Capacity Building and Information System}

The other challenge mentioned by the KIs was the lack of training on capacity building programs. Most of the KIs who were using computerized LMIS said that they were not able to use the computerized HCMIS effectively. Consequently, 
the software sometimes generated wrong reports. For instance, it revealed that the drug was completely expired though the drug was up to date. Because of this, the respondent strongly recommended that an IT professional was supposed to be urgently invited so as to overcome this computerized knowhow limitations. Unfortunately, the IT technician could be available after a week or more later, which results in overall work interruption in the HF. The other challenge mentioned by the KIs was lack of training about the laboratory reagents and supplies they managed. One of the respondents reported that he was simply managing these commodities without any piece of information about the use of the commodities. Some store managers who were using the computerized LMIS said that using both electronic and manual $\mathrm{BC}$ was redundant. Even if frequent interruption of electric power supply was a challenge, working only with the computer was good enough. That was why manual BCs were not updated most of the time. Another hindrance mentioned by some of the KIs was poor communication between program managers and pharmacy professionals. Consequently, KIs pointed out that doses of pediatrics drugs for TB treatment were changed before 3-4 months, but nobody was informing them regarding this regimen change. Finely, one of the respondents claimed that sometimes program managers were not considered as a principal part of the healthcare teams; as a result, they were provided by the necessary very lately.

\section{Challenges Related to Management Support}

Some of the respondents strongly mentioned that poor management support was considered as one of the most common factors. As for them, the head of the HF did not respond to their question in the main time or made any kind of follow-up on their work. They did not order the respective healthcare workers who did not report complete IFRR timely. For instance, one respondent said that the facility head may come to the store when only stock out happens. What is more, some of the respondents declared that major infrastructure problems like inadequate storage space, light problems, and lack of ventilators or air conditioners were challenges which were not solved by the facility managers. One respondent said that the HF had enough space to renovate the store but the facility manager failed to do so and, because of inadequacy of space, some drugs were in one store and some of them were in another store, which was not suitable for management. Another KI said that when the HF had no light access, the respondent went to the other HFs with accessible light to prepare a report since the power generator was functional only at night. The other challenge identified by KIs was lack of DUs' adherence to their schedule. Most of the store managers stated that DUs come on the same day for resupply, which would exacerbate the work load on the store managers. In the main time, they gave minimal attention to the quality of records, rather they focused on issuing the products. In addition, DUs brought false $\mathrm{SOH}$ reports because they did not use bin cards. The facility manager did not enforce DUs to be abided by their schedule and prepare quality report.

\section{Challenges Related to Inventory Management}

Lack of good practice to FEFO principle by PFSA was another challenge mentioned by KIs. According to the respondents, sometimes PFSA delivered products with long expiry for the first report and short expiry for the second report which was the major reason for expiry of products at the HFs. Longer lead time to resupply by PFSA was another challenge mentioned by respondents. As the respondents complained that PFSA usually deliver products after 1 month of report submission which could be one of the major reasons for stock out. There was frequent stockout of ethambutol $100 \mathrm{mg}, 400 \mathrm{mg}$, pediatric FDCRHZ, and INH $100 \mathrm{mg}$ from PFSA which was a constraint. In addition to the stock out of drugs, most of the KIs mentioned that frequent stock out of laboratory supplies and reagents were other challenges in delivering services.

On the other hand, one respondent said that the RRF he prepared did not include laboratory supplies because PFSA did not deliver to them. He procured a great deal of LCs once from private wholesalers. In contrast, PFSA allocated for HFs by itself whenever the commodities are available. Over supply or under supply of products by PFSA was mentioned as a challenge by respondents. One respondent said that 2 months earlier, kanamycin 100 pk was requested but PFSA resupplied $1000 \mathrm{pk}$, which was 10 -fold what was required. Because of this, they suffered for storage space. Lack of employed laboratory professionals who could work in the regional laboratory, lack of transport and power interruption were some of the most common challenges mentioned by KIs. All KIs working in gene Xpert sites raised power interruption as an impediment in which TB diagnosing laboratory reagents were wasted when there was no light.

\section{Discussion}

Well-functioning commodity management provides a reliable supply of commodities so that more people are 
likely to use superior health service. In addition, it provides reliable information to make an evidence-based decision and also reduces losses and stock out of commodities due to wastage and shortage, respectively. Therefore, there should be an appropriate inventory management performance to ensure a reliable supply of commodities. ${ }^{4}$ The finding of this study emphasized on inventory management performance using different indicators and challenges associated with commodity management at HFs level.

\section{LMIS Performance of Anti-TB}

\section{Commodities}

Findings of this research showed that all HFs were using LMIS tools like RRF and IFRR which were in line with research done in Oromia region, East Shewa zone. ${ }^{25}$ Four (25\%) HFs of the TB clinic and three (18.8\%) laboratory units which used $\mathrm{BCs}$ for stock control were against the standard of IPLS of the country, which states dispensing units should maintain a bin card for all commodities kept in DUs in order to make evidence-based decisions. ${ }^{14}$ The indepth interview also implicated that DUs brought false $\mathrm{SOH}$ data during reporting time due to non-utilization of bin cards. Our study also revealed that the $60 \%$ and $62.5 \%$ bin cards for first line and second line drugs being updated, respectively, was lower than research done in Namibia $(100 \%) .{ }^{26}$ This difference might be due to the type and quantity of products included. Consistent with this, the KIs had also pointed out workload in the store and relaying only on computerized recording system were mentioned as the reasons for not updating some of the manual bin cards. When we look for BCs accuracy rate in this research, the average BC accuracy rate for first line drugs (77.2\%) was comparable with an assessment done in Namibia (75\%). ${ }^{26}$

Regarding LCs, our study documented that none of the HFs had a bin card for all TB laboratory diagnostic reagents in the pharmacy store. This result was lower than a study done in Addis Ababa, which showed 50\% for hospitals and $54 \%$ for health centers. ${ }^{19}$ This difference may be due to the place where the commodities were managed. The majority of laboratory reagents were not managed in the pharmacy store in the present study, whereas in Addis Ababa, all laboratory reagents are managed in the main pharmacy store. ${ }^{19}$ In contrast to all these findings, the national standard states that any personnel responsible for the management of pharmaceuticals should maintain updated and accurate bin cards for each product in order to make evidence-based decisions. ${ }^{14}$

With regard to RRF accuracy, the result of this research showed that $75 \%$ of HFs reports were not accurate for at least $80 \%$ of anti-TB drugs. For second line drugs which were managed only in one hospital, half of the drugs were not accurately filled out on the report form. Consistent with these findings, an assessment in Malawi showed poor LMIS data quality or report inaccuracy, which is a major obstacle in the supply chain system. ${ }^{27}$ In addition to this, the KIs had also supported the existence of inaccurate logistic reports due to workload in the store. The finding of this research also identified the absence of LMIS-SOP which was a contributing factor in keeping logistic reports accurate. This was also true in the case of a study conducted in Nigeria which identifies lack of SOP that affects the quality of logistic data. ${ }^{28}$

In our study, none of the HFs had complete RRF because all lacked at least one essential data element from the report part such as ending balance at dispensing unit and loss/adjustment. It was higher than a study done in Addis Ababa which shows 7.7\% for HFs' report. ${ }^{29}$ The difference may be due to the type and quantity of commodities included, for example in a study done in Addis Ababa, only two anti-TB commodities are included. Our finding showed that $85.3 \%$ of TB clinics and $86 \%$ of laboratory units IFRR were complete, which contained beginning balance, stock on hand, quantity received, and loss/adjustment, which was comparable to a study done in Addis Ababa, which shows $87.5 \%$ HFs. In relation to this, the frequencies of reporting for TB clinics and laboratory units were $69.4 \%$ and $66.7 \%$, respectively, which shows poor adherence of schedule placed as per the standard of IPLS of the country. ${ }^{14,29}$

The nationally placed minimum-maximum inventory control system is intended to avoid placing emergency orders so that health facilities always have enough stock. Our finding showed that half of the HFs placed one or more emergency order for the past 6 months, which was in line with the national survey done for IPLS. ${ }^{16}$ In addition, the responses of the KIs have given an insight into the reasons behind placing an emergency order in which longer lead time to deliver products by PFSA was mentioned as a reason.

\section{Inventory Control System and Stock Status of Anti-TB Commodities}

According to order fill rate calculated for the drugs, the findings of this research showed that $62.5 \%$ of HFs were 
resupplied for at least $80 \%$ of products they requested. Anti-TB drugs which were used for adults like RHZE/ RH kit, INH $300 \mathrm{mg}$, and ethambutol $400 \mathrm{mg}$ were resupplied with the requested quantities in more than $70 \%$ of HFs for the last report, which was in line with the national IPLS survey that shows adult anti TB drugs like RHZE were resupplied in more than $70 \%$ of HFs. ${ }^{16}$ In addition, this finding showed that $68.7 \%$ and $62.5 \%$ of HFs received pediatric RH and RHZ, respectively, with the requested quantity. In association with this, the KIs reported that most of the time, stock out, or shortage of pediatrics antiTB drugs were occurred at PFSA, so that pediatrics drugs were not resupplied in the requested quantity.

Our finding showed that $11(68.8 \%)$ HFs were over stocked for ethambutol $100 \mathrm{mg}$ and INH $100 \mathrm{mg}$, whereas $10(62.5 \%)$ HFs was over stocked for adult TB kit, pediatric RH and INH $300 \mathrm{mg}$. In addition to this, six (37.5\%) HFs were under stocked for pediatric RHZ, whereas three (18.8\%) HFs were under stocked for INH $100 \mathrm{mg}$, RH, and RHZE/RH kit. In contrast to this finding, the national standard recommends the stock for any product should be always between maximum and minimum level. Both over stock and under stock are indicators of a poor inventory control system that will result in products for expiration and stock out, respectively. ${ }^{14}$

\section{Storage Condition}

With regard to storage condition, the finding of this study revealed that half of the study facilities did not fulfill the criteria of good storage condition ( $\geq 80$ positive response) which was comparable with the national survey of IPLS states $(55 \%)$ of the facilities. ${ }^{16}$ Regarding storage space, $43.8 \%$ of the facilities had no sufficient space for medicines storage and also free space for future expansion which leads to congestion and the inability to do inventory management. This was supported by the qualitative result in which insufficient storage space was mentioned as a challenge. In support of this finding, a research done in Namibia, Nigeria, and in sub-Saharan Africa shows that inadequate warehouse infrastructure (storage capacity) and inadequate warehouse management (lack of expertise of human resources and insufficient operational processes) are some of the challenges for good storage practice. ${ }^{26,30,31}$ The present study has also shown that storage guidelines have an association with good storage practice. In line with this, guidelines for improving performance of logistic management systems which are developed by USAID/DELIVER identified that storage guidelines are a factor that affects good storage practice results in lack of consistency in practice and non-accountability of staff. ${ }^{32}$

\section{Value of Wasted Medicines}

This study also described the value of wasted medicines due to expiry and damage. Based on this, a total of 84,275.04 Ethiopian birr was lost because of wastage of medicines. Parallel to this finding, a research done in Namibia shows there are a large amount of anti-TB drugs wasted due to expiry. ${ }^{26}$ As revealed by chi-square test, there was a statistically significant association between wastage and receiving near expiry medicines, failed to practice FEFO by the store manager and new regimen change by TB program which was the same as identified in Namibia. ${ }^{26}$ The qualitative result revealed that power supply was a challenge especially in those HFs that had gene Xpert machine resulting in wastage of laboratory reagents. This is also mentioned as a challenge in Nigeria which results in deterioration of laboratory diagnostic reagents. ${ }^{28}$

\section{Stock Out of Anti-TB Commodities}

The most important outcome of supply chain management is availability of stock at HFs. Stock outs in any health system represent a critical failure of the supply chain system. The finding of this research showed that pediatrics $\mathrm{RHZ}$ and RH were stocked out for the last 6 months in $50 \%$ and $31.3 \% \mathrm{HFs}$, respectively. In support of this finding, an assessment done in Malawi and west Gojjam Amhara region shows that sock out has occurred for these products. ${ }^{18,27}$ In consistence with this, the KIs mentioned that stock out and shortage of pediatrics FDC of anti-TB drugs were happening most of the time.

In the other way, this research finding showed that none of the HF was stocked out for RHZE/RH kit for the past 6 months which was in line with research done in East Shewa, Oromia region. ${ }^{25}$ But it was lower than a study done in Nigeria $(19.7 \%)^{30}$ and Tanzania (21\%). ${ }^{33}$ This difference may be due to TB kit implementation which was newly introduced in Ethiopia as compared to Nigeria in which more attention is given for the kit implementation, whereas Tanzania does not implement TB kit at the time of survey. Implementation of TB kit minimizes the risk of stock out and improves patient adherence to the drugs. ${ }^{5,34}$

Regarding availability of LCs, this study showed that $37.5 \%$ of HFs was stocked out for sputum cup on the day of visit which was higher than a study done in Amhara 
region which shows only $3.7 \% \mathrm{HFs}^{17}$ This difference may be due to the HFs assessed in Dire Dawa, which did not report supplies with drugs rather PFSA distributed with allocation which may contribute to stock out. A research done in Uganda also identifies the shortage of TB diagnosing supplies like sputum cup which support this finding. ${ }^{35}$ Additionally this research finding showed $40 \%$ HFs were stocked out for $1 \%$ basic carbon fuchsine which was parallel to research done in west Amhara region, Ethiopia $(41.3 \% \mathrm{HFs}){ }^{36}$ Finally the finding of this research showed that all HFs using a $\mathrm{ZN}$ microscope were stocked out for lens cleaning solution and lens paper at the time of visit, which is supported by research in west Gojjam. ${ }^{18}$ But, this finding was higher than a in a study done in west Amhara region that states microscope lens cleaning solution and lens paper were not found in $63.2 \%$ and $44.3 \%$ of HFs, respectively. ${ }^{17}$ The difference may be due to the sample size difference in the region. Lastly, this study revealed that a delay from PFSA to resupply, regimen change by program managers and low demand by clients were the most common reasons or contributing factors for stock out. This was also true in the case of the studies conducted in west Gojjam, Namibia, Malawi, and Nigeria which identified the same reasons for the observed stock out. ${ }^{18,-26-28}$

\section{Conclusion}

From our study, the availability and utilization of a bin card, updating practice, and accuracy of stock keeping record were found to be defective for the anti-TB commodities. Especially, for LCs, enough attention was not given in record keeping. Most facilities were not stocked according to the recommendation within the minimum and maximum of stock. For almost all products assessed, overstocking was higher than under stocking, leading to stock being wasted. Even though the availability of adult anti-TB drugs was generally good, there was some variation among facilities and product types and there were also frequent stock outs for pediatric anti-TB drugs and LCs which was an indicator of a weak supply chain.

In general, inventory management performance of anti-TB drugs, laboratory supplies, and reagents was found to be defective due to scarce human resources, deficient management support, lack of LCMs and HCMIS training, inappropriate utilization of LMIS tools, insufficient record and updating practice, inaccurate data, poor storage conditions, absence of storage guidelines, high stock out rate, long lead time, and wastage, which needs improvement. Ensuring an uninterrupted supply of anti-TB drugs and LCs used for TB diagnosis to all HFs is essential. Hence, respective organizations should improve their responsible activities to secure commodities availability.

\section{Abbreviations}

FDC, fixed dose combination; HCMIS, health commodities management information system; HFs, health facilities; IFFR, internal facility reporting and requisition from; IPLS, integrated pharmaceutical logistic system; LMIS, logistic management information system; MTB/RIF, Mycobacterium Tuberculosis/rifampicin test; PFSA, Pharmaceutical Fund and Supply Agency; RRF, report and requisition format; SOP, standard operating procedures.

\section{Data Sharing Statement}

Data can be obtained from the corresponding author upon request.

Supporting Information: Questionnaires and observation checklists to collect data to assess anti-tuberculosis commodities management performance and factors affecting it at public health facilities in Dire Dawa city administration, Ethiopia are available in Supplementary File S1.

\section{Acknowledgments}

We are grateful to Jimma University and Dire Daw city administration Health Bureau for their kind support. We would also like to thank all health facilities for their kind and cooperative response to our inquiries information.

\section{Disclosure}

The authors report no conflicts of interest in this work.

\section{References}

1. Senedu BG, Solomon AY, Gunnar AB. Qualitative assessment of challenges in tuberculosis control in West Gojjam Zone, Northwest Ethiopia: health workers and tuberculosis control program coordinators' perspectives. Tuberc Res Treat. 2016;2016.

2. Firew TK, Teklehaimanot MN, Gebremedhin BG. Assessment of knowledge and attitude of tuberculosis patients in direct observation therapy program towards multidrug-resistant tuberculosis in Addis Ababa, Ethiopia: a cross-sectional study. Tuberc Res Treat. 2020;2020.

3. Addisu AG, Megbaru D, Kalid S, et al. Assessment of anti-TB drug non-adherence and associated factors among TB patients attending TB clinics in Arba Minch governmental health institutions, Southern Ethiopia. Tuberc Res Treat. 2018;2018.

4. World health organization. Global tuberculosis report. Geneva Swezerland; 2017.

5. Federal Ministry of Health. National guideline for TB, DR-TB and leprosy in Ethiopia. 2017.

6. Federal ministry of health. Guidelines for clinical and programmatic management of TB, TB/HIV and leprosy in Ethiopia. 2013. 
7. Jatau B, Avong Y, Ogundahunsi O, et al. Procurement and supply management system for MDR-TB in Nigeria: are the early warning targets for drug stock outs and over stock of drugs being achieved? PLoS One. 2015;10(6):1-10. doi:10.1371/journal.pone.0128500

8. Kibriti M, Tsehaye A, Haftamu H, et al. Prevalence and factors associated with multidrug-resistant tuberculosis (MDR-TB) among presumptive MDR-TB patients in Tigray Region, Northern Ethiopia. Can J Infect Dis Med Microbiol. 2019;2019.

9. Management science for health. Management strategy in improving health service. Vol. 10. 2013:1125-1156.

10 . World health organization. Guidance for countries on the specifications for managing TB laboratory equipment and supplies. Geneva, Switzerland; 2012:10-176.

11. World health organization. Tuberculosis medicines technology and market landscape. Geneva Swezerlan; 2013.

12. USAID/DELIVER. The Logistics Handbook: A Practical Guide for the Supply Chain Management of Health Commodities. 2nd ed. Arlington; 2011:6-50.

13. Damtie TA, Ibrahim AJ, Yikna BB. Supply chain management performance of HIV/AIDS commodities and factors affecting it at health facilities of SNNPRS of Ethiopia; from the perspective of achieving 90- 90-90Strategies. Integr Pharm Res Pract. 2020;9:11-20. doi:10.2147/IPRP.S228162

14. Pharmaceutical fund and supply agency. Standard Operating Procedures (SOP) Manual for the Integrated Pharmaceuticals Logistics System in Health Facilities of Ethiopia. 2nd ed. Ethiopia: PFSA; 2015:7-56.

15. Embrey M. Managing Access to Medicines and Health Technologies. Arlington, VA; 2012:1125-1267.

16. Pharmaceutical fund and supply agency. National survey of the integrated pharmaceutical logistics system. 2015.

17. Sinishaw MA, Gebregergs GB. Distribution and availability of essential tuberculosis diagnostic items in Amhara. PLoS One. 2015;10 (12):1-8. doi:10.1371/journal.pone.0141032

18. Gebreegziabher SB, Yimer SA, Bjune GA. Qualitative Assessment Of Challenges In Tuberculosis Control In West Gojjam Zone, Northwest Ethiopia: Health Workers ' and Tuberculosis Control Program Coordinators 'Perspectives. Hindawi Publ Corp; 2016:1-8.

19. Desalegn A, Taye BG. Assessment of laboratory logistics management information system practice for HIV/AIDS and tuberculosis laboratory commodities in selected public health facilities in Addis Ababa, Ethiopia. Pan African Med Journal. 2013;15(1).

20. USAID/DELIVER. Laboratory Logistics Handbook. 2009.

21. Sporrong SK, Traulsen JM, Kabtimer WD, Habtegiorgis BM, Teshome D. Developing and Sustaining Human Resources in the Health Supply Chain in Ethiopia: Barriers and Enablers. 2016:1-11.

22. Dire Dawa city administration office. Dire Dawa city administration socio- demographic data. 2010.
23. USAID/DELIVER. Logistic Indicators Assessment Tools (Liats). Arlington, VA;2005:1-42

24. USAID | DELIVER Project to 1. Logistics indicators assessment tool (LIAT). Arlington; 2008. Available from: https://pdf.usaid.gov/pdf docs/Pnade735.pdf. Accessed January 19, 2019.

25. Gurmu TG, Ibrahim AJ. Inventory management performance of key essential medicines in health facilities of East Shewa Zone, Oromia Regional State, Ethiopia. Cukurova Med J. 2017;42(2):277-291. doi:10.17826/cutf.322908

26. Owunna C, Chana CR, Ntege CN. Assessment of the TB pharmaceutical management system in Namibia. Arlington, VA; 2011.

27. Chana RC Assessment of the logistics and supply chain management of anti-TB medicines. Report No.1. Arlington; 2011.

28. Omo-emmanuel UK, Chinedum OK, Michael O, Negedu-momoh O. Evaluation of laboratory logistics management information system in HIV/AIDS comprehensive health facilities in Bayelsa State, Nigeria. Int J Curr ResMed Sci. 2017;3(1):21-38.

29. Tilahun A, Geleta DA, Abeshu MA, Geleta BB. Assessment of integrated pharmaceutical logistic system for the management of HIV/AIDS and tuberculosis laboratory diagnostic commodities in public health facilities in Addis Ababa, Ethiopia. J Pharm Care Heal Syst. 2016;3(2):1-10.

30. Gulma K, Abubakar M, Mohammed BL, et al. Stock status assessment of health commodities used in the management of HIV/AIDS and TB in Kano state, Nigeria. J Pharm Res. 2015;14(2):33-41. doi:10.18579/jpcrkc/2015/14/2/79075

31. Schöpperle A. Analysis of challenges of medical supply chains in sub-Saharan Africa regarding inventory management and transport and distribution. Westminster, London; 2013.

32. USAID/DELIVER. Guide for malaria commodities logistic management system; MTP approach for improving performance of logistic management system. Arlington, VA: Management Sciences for Health; 2013:3-69.

33. Jaya C, Joy K, Jennifer TS. Tanzania TB and leprosy logistics system assessment. quantitative and qualitative results from the LIAT and the LSAT. Report No. 1. Arlington, VA; 2011.

34. Rational Pharmaceutical Management (RPM) Plus. Patient kits promote good tuberculosis pharmaceutical management. 2010.

35. Cattamanchi A, Miller CR, Tapley A, et al. Health worker perspectives on barriers to delivery of routine tuberculosis diagnostic evaluation services in Uganda: a qualitative study to guide clinic-based interventions. BMC Health Serv Res. 2015;15:10.

36. Shiferaw MB, Hailu HA, Fola AA, et al. Tuberculosis laboratory diagnosis quality assurance among public health facilities in West Amhara Region, Ethiopia. PLoS One. 2015;10(19):10-18. doi:10. 1371/journal.pone.0138488
Journal of Multidisciplinary Healthcare

\section{Publish your work in this journal}

The Journal of Multidisciplinary Healthcare is an international, peerreviewed open-access journal that aims to represent and publish research in healthcare areas delivered by practitioners of different disciplines. This includes studies and reviews conducted by multidisciplinary teams as well as research which evaluates the results or conduct of such teams or healthcare processes in general. The journal covers a very wide range of areas and welcomes submissions from practitioners at all levels, from all over the world. The manuscript management system is completely online and includes a very quick and fair peer-review system. Visit http://www.dovepress.com/testimonials. php to read real quotes from published authors. 